Peñaloza, V., Portela, M., S. O., Gerhard, F. \& Quezado, I. (2018). Representação Social da Compra por Impulso por Consumidores de Baixa Renda. Consumer Behavior Review, 2(1), 1-12.

ISSN: 2526-7884

Editor: Prof. Dr. Marconi Freitas da Costa

Email da revista: cbr@ufpe.br
Avaliação: Double blind review

Recebido: 15 de janeiro de 2017

Aceito: 04 de junho de 2017

\title{
REPRESENTAÇÃO SOCIAL DA COMPRA POR IMPULSO POR CONSUMIDORES DE BAIXA RENDA
}

\author{
Verônica Peñaloza \\ Mayara Soares Oliveira Portela \\ Felipe Gerhard \\ Izabelle Quezado
}

Verônica Peñaloza é Professora do

Programa de Pós-Graduação em Administração da Universidade Estadual do Ceará - UECE. E-mail:

veronica.penaloza@uece.br.

Mayara Soares Oliveira Portela é

Mestranda em Administração pela

Universidade Estadual do Ceará - UECE.

E-mail: mayaraportela87@gmail.com.

Felipe Gerhard é Doutorando em

Administração pela Universidade

Estadual do Ceará - UECE. E-mail: gerhard.sousa@aluno.uece.br.

Izabelle Quezado é Doutoranda em

Administração pela Universidade de

Fortaleza - UNIFOR. E-mail:

izabellequezado@gmail.com.

Os autores agracedecem aos avaliadores pelos comentários para melhoria do artigo.

\begin{abstract}
Resumo
Apesar do avanço na compreensão do consumo impulsivo no meio acadêmico, são poucas as pesquisas dedicadas a que explorar o fenômeno com enfoque em consumidores de baixa renda. Frente a essa lacuna teórica, este estudo objetiva compreender o comportamento impulsivo do consumidor de baixa renda, analisando a construção coletiva da compra por impulso por meio da teoria das representações sociais. Para tal, com base na técnica de evocação de palavras, entrevistas estruturadas de curta duração foram realizadas em um corpus de pesquisa composto por 306 pessoas com diferentes características sociodemográficas. Os resultados indicam que a representação social do consumo impulsivo é constituída por um amálgama de conceitos heterogêneos, com características divergentes entre classes sociais. Ademais, três conceitos se destacam como os mais representativos para a compreensão do fenômeno: falta de planejamento, descontrole/exagero e dívidas/endividamento; revelando uma construção social composta tanto por elementos normativos e funcionais, como por consequências de conotação negativa.

Palavras-Chave: Consumo Impulsivo, Consumidores de BaixaRenda, Representação Social.
\end{abstract}




\section{INTRODUÇÃO}

$\mathrm{Na}$ seara do marketing, pesquisas iniciais em comportamento do consumidor já apontavam a relevância de se explorar a compra impulsiva (por exemplo: Clover, 1950; Stern, 1962; Kollat \& Willett, 1967; Rook, 1987). Isso se deve ao fato de que até $62 \%$ das compras em lojas varejistas podem ser consideradas impulsivas (Rook, 1987). Do mesmo modo, em estudo desenvolvido no Brasil pelo Serviço de Proteção ao Crédito (SPC), identificou-se que $52 \%$ da amostra havia realizado uma compra por impulso nos três meses anteriores à pesquisa. Desse percentual, $41 \%$ declarou estar endividado (SPC, 2015).

Vários são os elementos que propiciam o aumento e a generalização do comportamento de compraimpulsiva em todo o mundo. Fatores sociais, culturais, econômicos, psicológicos, ambientais e mercadológicos influenciam o indivíduoe suas ações em relação ao consumo (Muruganantham \& Bhakat, 2013). Inovações como o uso de cartões de crédito, caixas eletrônicos com acesso a crédito imediato, lojas abertas 24 horas etelemarketing propiciam a compra por impulso (Rook, 1987).

Assim, a complexidade crescente do comportamento de compra dos indivíduos e a natureza multifacetada do consumo por impulso ainda fazem deste um desafio para os pesquisadores (Lima, Gosling \& Matos, 2008). Frente a essa diversidade, a compra impulsiva é tópico de diversos estudos em âmbito acadêmico (Araújo \& Ramos, 2010; Tinne, 2011; Roberts \& Manolis, 2012; Porpino \& Parente, 2013; Lucas \& Koff, 2014; Dias, Santos, Martins \& Isabella, 2014; Ladeira, Santini \& Araújo, 2016).

São poucas as pesquisas, porém, que exploram o fenômeno com enfoque em consumidores de baixa renda (Lima, Gosling, \& Matos, 2008). Em âmbito internacional, as pesquisas recentes com enfoque nesse segmento, incluem abordagens de percepção de ética em estratégias de marketing (Gupta \& Pirsch, 2014), preço e adoção de novos produtos (Christensen, Siemsen \& Balasubramanian, 2015), aspirações de consumo (Gupta \& Pratish, 2016), globalização de mercado e práticas de consumo (Yurdakul, Atik \& Dholakia, 2017).
Entre os países latinos, a literatura brasileira reúne o maior número de estudos voltados ao consumo na baixa renda (Kolk, Riviera-Santos \& Rufin, 2014), contemplando o tratamento de variáveis como marketing de relacionamento, lealdade à marca e proposição de valor (Barki \& Parente, 2010); hedonismo e moralismo (Hemais, Casotti \& Rocha, 2013) e expectativa em torno do varejo (Antoni \& Basso, 2016).

Emgeral, tais estudos enfocam em tomada de decisão de alocação de recursos e prioridades de consumo (Chauvel \& Mattos, 2008). Desse modo, restringem-se à investigação do consumo planejado do consumidor de baixa renda, sendoa compra por impulso pouco ou nada explorada, o que se configura como uma lacuna teórica que este artigo contribui para preencher.

É válido ressaltar, ainda, que o consumo impulsivo merece atenção de estudos acadêmicos, sobretudo por trazer, como consequência, danos financeiros ao consumidor (Araújo \& Ramos 2010; Porpino \& Parente, 2013). Essa constatação é mais preocupante em classes sociais menos abastadas, uma vez que a facilidade de acesso ao crédito, disseminada atualmente no Brasil, favorece a compra por impulso (Rook, 1987).

Diante do exposto, este artigo objetiva compreender o comportamento impulsivo do consumidor da baixa renda, analisando a construção coletiva da compra por impulso por meio da teoria das representações sociais. Para tanto, foi realizado um estudo exploratório de natureza qualitativa e quantitativa. 0 levantamento se deu por meio de entrevista estruturada de curta duração, utilizando a técnica de evocação de palavras como suporte para a condução das entrevistas.

Vale destacar que o presente estudo contribui para atenuar a lacuna metodológicainerente ao uso de evocação de palavras no campo da Administração. Ademais, a pesquisa é relevante para o setor gerencial, uma vez que explora a compra por impulso na baixa renda, classe socialdetentora de grande potencial de consumo. Setores emergentes são foco das empresas locais e corporações internacionais, as quaisdevem ajustar suas estratégias e buscar novos modelos de negócio adequados a esse segmento (Peñaloza, Denegri \& Gerhard, 2015). 
Além desta introdução, o artigo é composto por uma revisão dos principais aspectos teóricos relacionados ao tema de consumo impulsivo, sintetizados na fundamentação teórica. Em seguida, são apresentados os procedimentos metodológicos onde se destacam as representações sociais e, posteriormente, à luz dos resultados, é apresentada uma discussão da pesquisa empírica. Finalmente, apresentam-se as considerações finais do artigo.

\section{FUNDAMENTAÇÃO TEÓRICA Consumo impulsivo}

Após a Segunda Guerra Mundial, quando houve a retomada do poder de consumo, surgiu na comunidade acadêmica o interesse pelo estudo do comportamento de compra impulsivo, com destaque aos trabalhos pioneiros de Clover (1950) e Applebaum (1951), que apresentam pesquisas exploratórias inerentes às características da compra por impulso no ambiente de varejo.

No estudo desses autores, conceitua-se o consumo impulsivo como aquele que não é planejado pelo indivíduo antes de chegar à loja, mas que, frente aos estímulos de promoção de venda, vem a se firmar (Clover, 1950; Applebaum, 1951). Assim, nos primeiros estudos sobre consumo impulsivo, a compra não planejada tornou-se sinônimo do comportamento impulsivo. Apesar de ser uma característica fundamental, a literatura mais recente esclarece que a falta de planejamento não é suficiente para conceituar o consumo impulsivo (Araújo \& Ramos, 2010; Porpino \& Parente, 2013).

A compra por impulso está estritamente relacionada à personalidade do consumidor (Weinberg \& Gottwald, 1982; Dholakia, 2000; Dias et al., 2014) e é um processo ativado emocionalmente mediante o desejo repentino e persistente de comprar. Quando a componente emoção aumenta, a capacidade de processamento cognitivo diminui, podendo emergir, assim, a impulsividade. Portanto, o consumo impulsivo está mais associado à relação entre emoções e processamento cognitivo que somente a este (Porpino \& Parente, 2013). Ainda, sabe-se que o consumidor impulsivo dá ênfase ao momento presente e está propenso a subestimar as consequências da compra por impulso, como não honrar as suas dívidas (Siqueira, Castro, Carvalho \& Farina, 2012; Dias et al., 2014). Tal característica também se configura como componente cognitivos fundamental do consumo impulsivo (Beatty \& Ferrel, 1998; Youn, 2000; Lucas \& Koff, 2014).

Além dos aspectos cognitivos e de personalidade, o comportamento do consumo por impulso é também afetado pelo ambiente de consumo (Shahjehan, Qureshi, Zeb \& Saifullah, 2011). As estratégias de merchandising criam uma atmosfera favorável a esse tipo de comportamento e a utilização de uma comunicação efetiva desperta o interesse do consumidor, podendo induzi-lo à compra por impulso (Araújo \& Ramos, 2010; Siqueira et al., 2012). O layout dos modernos centros de consumo é projetado com o intuito de gerar uma explosão de estímulos no consumidor, de modo a limitar o potencial de seu processamento cognitivo de informações, despertando a dimensão hedônica do indivíduo (Lipovetsky, 2007; Baudrillard, 2011).

Assim, haja vista a gama de aspectos que podem desencadear a compra impulsiva, esta vem sendo amplamente investigada em pesquisas recentes em âmbito internacional (e.g., Tinne, 2011; Roberts \& Manolis, 2012; Lucas \& Koff, 2014) e nacional (e.g., Santini \& Espartel, 2010; Araújo \& Parente, 2013; Dias et al., 2014; Ladeira, Santini \& Araújo, 2016).

0 estudo de Tinne (2011) testa o impacto de diversos fatores na compra por impulso, como desconto, comportamento do vendedor, popularidade do produto e influência de grupos de referência. Roberts e Manolis (2012), por sua vez, relacionam o autocontrole com a compra impulsiva e, conforme esperado, aponta que a ausência de autocontrole favorece o consumo por impulso. Com enfoque no público feminino, Lucas e Koff (2014) exploram o efeito da autopercepção de atratividade no consumo impulsivo eindicam que, quanto mais atrativas as mulheres julgam ser, maior a propensão de realizarem compras por impulso.

Em âmbito nacional, Ladeira, Santini e Araújo(2016) apresentam uma meta-análise sobre antecedentes e consequentes do materialismo e destacam, como consequente, a compra por impulso. 0 estudo de Porpino e Parente (2013) aponta como antecedentes da compra impulsiva as estratégias de promoção 
desenvolvidas pelas empresas. Como consequentes, os autores pontuam o medo e o endividamento. Também investigando a temática, Santini e Espartel (2008) analisam a influência da promoção de vendas na incidência de compras impulsivas e constatam resultados que confirmam tal relação.

Costa e Larán (2003) exploram a compra por impulso na Internet em um modelo teórico que relaciona este construto à impulsividade individual, e ao ambiente virtual de loja, identificando que a compra impulsiva é pouco influenciada pelo meio, sendo, sobretudo, resultado de falhas de comportamento. Também direcionado a explorar o ambiente virtual, mais especificamente de compras coletivas, Dias et al. (2014) relacionam estratégias de marketing e impulsividade e encontram uma relação pouco relevante. Ambos os estudos, porém têm amostras compostas por consumidores de classes sociais mais altas.

Lima, Gosling e Matos (2008), por sua vez, investigam a compra impulsiva do consumidor de baixa renda, considerando valores, significado, ambiente e promoção no ponto de venda. Os autores ressaltam que, embora tenham apresentado relações significativas, os referidos construtos não englobam todos os aspectos que afetam o comportamento de compra impulsivo na baixa renda e sugerem a continuidade da investigação em torno do tema.

\section{Teoria das representações sociais}

A Teoria das Representações Sociais tem sua origem na Psicologia Social e surge como uma opção para as pesquisas de administração, pois estas muitas vezes envolvem fenômenos complexos, nos níveis individual, organizacional ou social, cujo entendimento não pode ser buscado a partir de abordagens reducionistas, que não contemplem a complexidade que caracteriza a ação humana (Vergara \& Ferreira, 2007).

Desenvolvida inicialmente por Serge Moscovici, psicólogo nascido na Romênia que se naturalizou francês, a representação social foi objeto de estudo de seu doutorado, acarretando a publicação, em 1961, do seu livro La Psychanalyse: son image et son public (Vergara \& Ferreira, 2007). Nesta obra, Moscovici estudou as várias formas pelas quais a
Psicanálise era percebida, ou seja, representada e difundida entre os parisienses.

Oliveira (2004) destaca três importantes itens desta obra. 0 primeiro item observado é que as representações sociais encontradas posicionavam-se entre os conceitos científicos de Psicanálise e o entendimento da sociedade sobre o assunto; o segundo ponto destacado é que as pessoas entrevistas não compartilhavam da mesma representação, pois divergiam de acordo com o conhecimento de senso comum e o contexto sociocultural em que os indivíduos estavam inseridos; a última observação foi de que o procedimento de elaboração de uma representação diante de uma nova informação segue uma sequência lógica de duas operações: a amarração, ou ancoragem, que é a procura de tornar o que é desconhecido em conhecido, e a objetivação, que é o processo de conexão das imagens e experiências vividas no cotidiano para a formação dos novos conceitos.

Um dos principais argumentos defendidos por Moscovici é a de que as ações dos indivíduos e das coletividades são baseadas nas suas representações sociais e não necessariamente na realidade. De acordo com Mendonça e Lima (2014), as representações sociais surgem por meio da necessidade de ajustamento das pessoas, ou seja, tornar o desconhecido em conhecido, e para isso necessitam identificar, conduzir e resolver problemas que lhes são apresentados. Nesse processo de ajustamento, de superação do "vago", os sujeitos são capazes de compreender os grupos externos aos seus grupos de pertença, realizando uma "economia" cognitiva.

O estudo das representações sociais podem fornecer informações capazes de proporcionar uma visão geral do que é o homem em sua interação com as ideias ou com os objetos, assim as pesquisas sobre representações sociais podem ser consideradas elementos imprescindíveis para uma melhor compreensão da sociedade. Pode-se então dizer que cada pessoa possui um papel ativo na construção da realidade. Ao mesmo tempo, esta mesma pessoa é formada por esta realidade, pois a representação social é construída e compartilhada socialmente (Barbieri, 2015; Franco, 2004). Assim, resulta pertinente realizar pesquisas sobre consumo por impulso à luz da Teoria das Representações Sociais. 


\section{METODOLOGIA}

Frente ao intuito de analisar a representação do conceito de consumo impulsivo, uma pesquisa empírica foi realizada em uma cidade do nordeste brasileiro, região onde mais da metade $(54,8 \%)$ das famílias residentes em domicílios permanentes têm um rendimento médio mensal familiar de até dois salários mínimos (PNAD, 2013). A técnica escolhida para a coleta de dados foi a evocação de palavras, raramente utilizada em Administração e apontada por Möller (1996) e Vergara e Ferreira (2007) como o principal meio para o mapeamento dos significados fundamentais de representação social.

\section{Participantes}

0 corpus de pesquisa é composto por 306 indivíduos. Apesar do corpus ser formado por pessoas de ambos os sexos, de diferentes idades e graus de instrução, quase a totalidade dos entrevistados encontram-se em estratos sociais mais vulneráveis. Para a obtenção dos respondentes, foi utilizada uma técnica de amostragem intencional de caráter incidental, em que, embora um grupo populacional específico tenha sido selecionado por escolha dos pesquisadores, os sujeitos entrevistados na pesquisa foram selecionados por acaso (Aaker, Kumar \& Day, 1995). O critério utilizado para encerrar o corpus de pesquisa em 306 indivíduos foi a saturação dos dados. Ao se perceber que, apesar do incremento de entrevistas adicionais, novas unidades e grupos semânticos não eram emersos do campo, os pesquisadores decidiram por concluir a pesquisa empírica.

\section{Instrumento}

Com o objetivo de alçar significados e sintetizar os principais conceitos relacionados a consumo impulsivo na opinião de um determinado grupo de indivíduos, foi utilizada a técnica de evocação de palavras (Vergara \& Ferreira, 2007). Por meio da técnica, os pesquisadores solicitaram aos entrevistados que mencionem as quatro primeiras palavras que lhes vêm à mente quando a expressão indutora "consumo impulsivo" era apresentada.

Após o fim da etapa inicial da entrevista, foram realizadas perguntas para 0 levantamento de dados sociodemográficos dos respondentes, quais sejam: sexo, idade, estado civil, grau de instrução, renda familiar, número de integrantes do grupo familiar e trabalho do chefe de família.

\section{Procedimentos}

As entrevistas foram realizadas durante os meses de outubro de 2015 a março de 2016, em terminais rodoviários da cidade de Fortaleza. A razão para a seleção de terminais rodoviários como lócus da pesquisa se justifica pelo conhecimento prévio dos pesquisadores quanto ao estrato socioeconômico médiodos seus usuários - característica estatisticamente comprovada após análise descritiva dos dados. Antes do início das entrevistas, os pesquisadores explicaram aos respondentes que a participação no estudo era voluntária e que além das informações relatadas serem anônimas, tinham como objetivo a consecução de um estudo científico. Apesar de se caracterizar como uma entrevista estruturada, os pesquisadores não tolhiam o discurso dos respondentes, possibilitando a coleta de informações adicionais. Geralmente os entrevistados se delongavam na explicação dos termos mencionados, o que elevou o tempo de entrevista a cerca de 8 minutos. Os dados colhidos foram trabalhados com auxílio do software Statistical Package for the Social Sciences (SPSS) versão 20.0.

\subsection{Análise de Dados}

Para a análise das palavras e expressões emersas por meio da técnica de evocação de palavras, foram filtradas, inicialmente, as unidades semânticas relevantes à pesquisa. Em seguida, as unidades foram agrupadas de acordo com a similaridade de sentido apresentada, constituindo categoriassignificado referentes ao objeto de pesquisa em análise. Em seguida, foram avaliadas as forças semânticas dos grupos levantados e construído um gráfico cartesiano que evidencia a distribuição de cada categoria entre os seus quadrantes.

Para análise dos dados foram utilizadas as técnicas de estatísticas descritivas básicas e análise de correspondência na construção dos mapas perceptuais- usados como forma de representação visual das relações complexas entre as palavras mencionadas e outros 
atributos. O escalonamento multidimensional, também conhecido como mapeamento perceptual, é um procedimento que permite determinar a imagem relativa percebida de um conjunto de atributos, cujo objetivo é transformar as informações em distancias representadas no espaço multidimensional. Uma das técnicas mais populares para a redução dimensional chama-se análise de correspondência, um procedimento que permite determinar a imagem relativa percebida de um conjunto de objetos (Hair, Black, Babin, Anderson \& Tatham, 2005).

\section{ANÁLISE DOS RESULTADOS}

Nesta seção, foram analisados os principais resultados encontrados na pesquisa. As informações estão divididas em dois tópicos. Incialmente, apresenta-se as características gerais do corpus de pesquisa bem como os resultados referentes à construção da representação social erigida. Em seguida, há uma discussão mais aprofundada dos resultados da pesquisa.

\section{Caracterização do Corpus e Construção do Gráfico Representacional}

Dos 306 respondentes que compõem o corpus de pesquisa, 162 são homens e 154 são mulheres, com idades que flutuam entre 16 e 66 anos e média de 29,42 anos. Ao se analisar o perfil dos entrevistados de acordo com as categorias sociais do IBGE, baseada no quesito renda, 46 respondentes estariam classificados na classe C, 106 na classe D e 143 na classe E. Esses resultados demonstram que os indivíduos entrevistados têm como característica comum um perfil social mais vulnerável.

Por conseguinte, são analisados os dados coletados nas entrevistas. Por meio da expressão indutora "consumo impulsivo", foram evocadas 1.158 palavras ou expressões diferentes de um total de 1.271, reunidas posteriormente em categorias de acordo com a aderência semântica das unidades linguísticas levantadas. Destas, 113 palavras ou expressões foram excluídaspor no mínimo um dos seguintes motivos: não possuir similaridade semântica com os grupos definidores; apresentar baixa frequência de citação, ou; não representar contribuição relevante para a análise - e.g., Jesus Cristo, ociosidade, mulher, poluição, pneu furado e vazio, entre outras.

Ato contínuo, as unidades de sentido restantes foram classificadas em 15 grupos definidores, de acordo com as suas similaridades semânticas. Em seguida, se iniciou a construção do quadrante de evocação com os grupos semânticos alçados tanto através da análise da literatura quanto por meio da pesquisa empírica (Vergara \& Ferreira, 2007). $\mathrm{Na}$ Figura 1, foram esquematizados os resultados da categorização, de acordo com a sua frequência absoluta de aparição e com a Ordem Média de Evocação (OME), i.e., uma frequência ponderadaque considera a posição que a resposta foi mencionada.

O esquema indica a relevância alcançada por cada grupo semântico na análise. As categorias situadas no primeiro quadrante possuem importância central no estudo, i.e., suas evocações possuem maior frequência e importância de aparição. Os grupos definidores que compõem o primeiro quadrante são: Descontrole / Exagero; Sem Pensar / Não Planejado; e Dúvidas. Segundo a visão de Abric (2001), o sistema central seria o elemento mais estável da representação e estaria definido por elementos de natureza normativa e funcional

As categorias localizadas no segundo e no quarto quadrantes apresentam importância periférica, ou seja, são relevantes para a análise embora não apresentem a força consensual obtida pelas categorias presentes no primeiro quadrante. Para Abric (2001), o sistema periférico é mais flexível, estaria formado pelos elementos de contexto que permitem a fixação da representação na realidade do momento.

Os grupos definidores neste caso seriam Roupa / Calçados / Acessórios; Produtos / Serviços; Alimentos / Comida; Desnecessário; Sentimentos Negativos, que constituem o quadrante periférico de frequência maior que a média, mas com ordem de evocação menor (Quadrante II), e o grupo, Compras/Comprar, (Quadrante IV) também periférico, mas que apresenta menor frequência, porém é citado com maior prioridade. Por fim, apesar de trazerem conceitos pertinentes a grupos específicos, as categorias identificadas no terceiro quadrante possuem menor importância para análise por terem uma ordem de prioridade e frequência de citações menores 
que a média, quais sejam: Lazer, Desejo, Sentimentos Positivos e Doença.

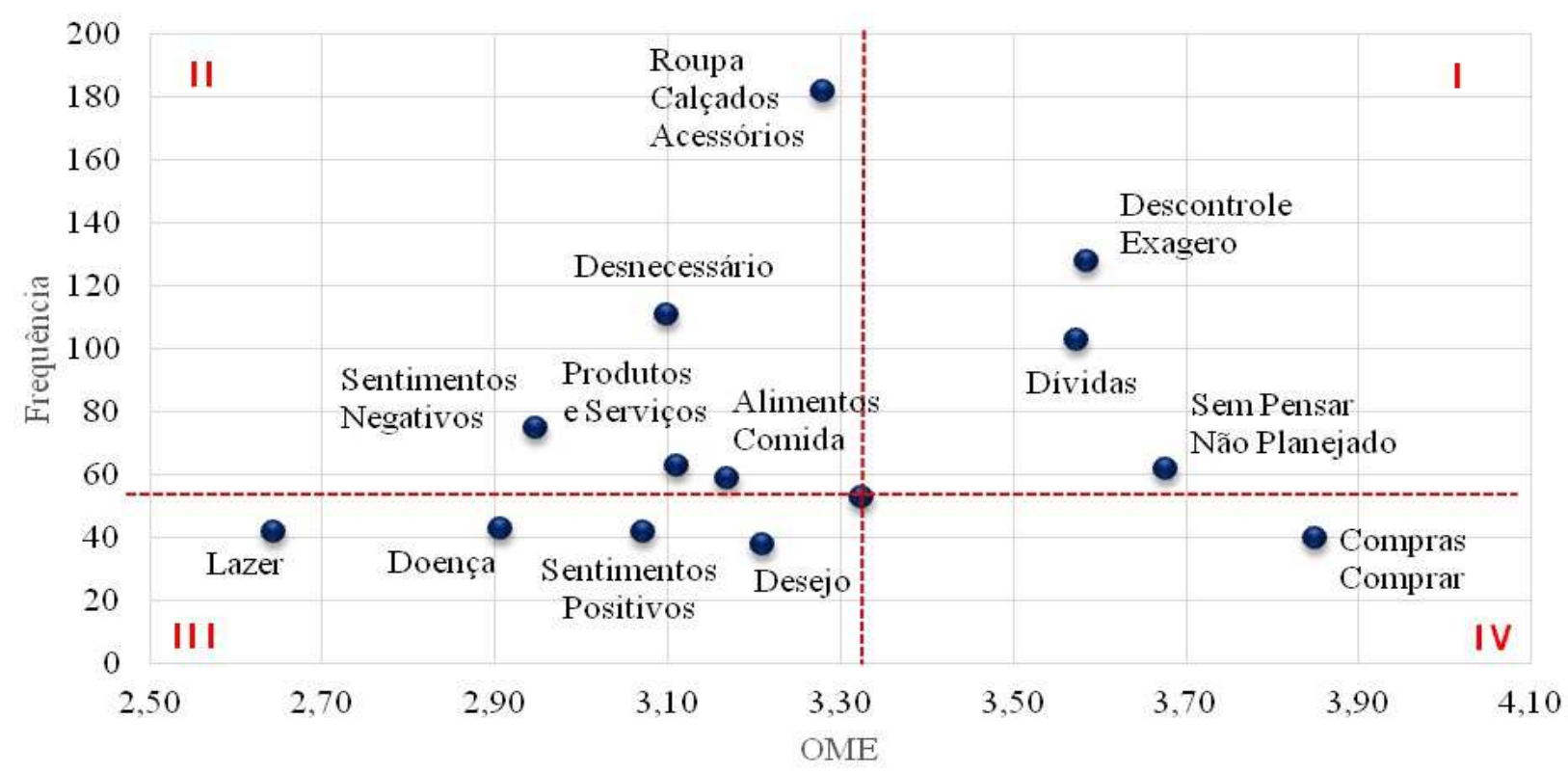

Fonte: Elaborado pelos autores.

Figura 1. Representação Social do Consumo Impulsivo

A Figura 2, a seguir, revela o mapeamento dos grupos definidores por classes de renda. Em torno da classe E se aglutinam os grupos de Roupa / Calçados e Acessórios; Alimentos / Comida; Produtos / Serviços e também Doença e Desejo. Já a classe D concentra os grupos Sem Pensar / Não Planejado; Desnecessário e os Sentimentos Positivos e Negativos.Por sua vez, a classe $\mathrm{C}$ pode ser associada ao grupo Descontrole / Exagero. Os resultados mostram claramente que a representação social do consumo impulsivo difere entre classes de renda.

A proximidade das classes socioeconômicas com unidades semânticas distintas revela a heterogeneidade presente na representação do consumo impulsivo. A renda, portanto, se caracteriza como um fator capaz de alterar a percepção dos indivíduos em relação à impulsividade, mesmo em estratos com limitação financeira acentuada. No que concerne às unidades citadas por cada estrato, observa-se que o grupo de consumidores pertencentes às classes $\mathrm{C}$ e $\mathrm{D}$ mencionaram expressões que indicam uma dispersão da racionalidade utilitária, pontuando características menos pautadas em restrições financeiras para destacar o papel da ação individual na formação do consumo impulsivo.

As unidades mencionadas pela classe $\mathrm{E}$, por outro lado, indicam elementos eminentemente presentes em seu dia-a-dia. Uma vez que está estreitamente relacionado às suas necessidades diárias, o consumo impulsivo deixa de ser entendido como uma responsabilidade individual para ressaltar o papel do seu próprio contexto sócio-material. Revelam, ademais, a proximidade com a qual lidam com o fenômeno da impulsividade no consumo; a qual auxilia, inclusive, a moldar o seu cotidiano.Com efeito, tais indivíduos necessitam apresentar um alto grau de austeridade financeira pra que sua situação econômica não fuja do controle orçamentário. 


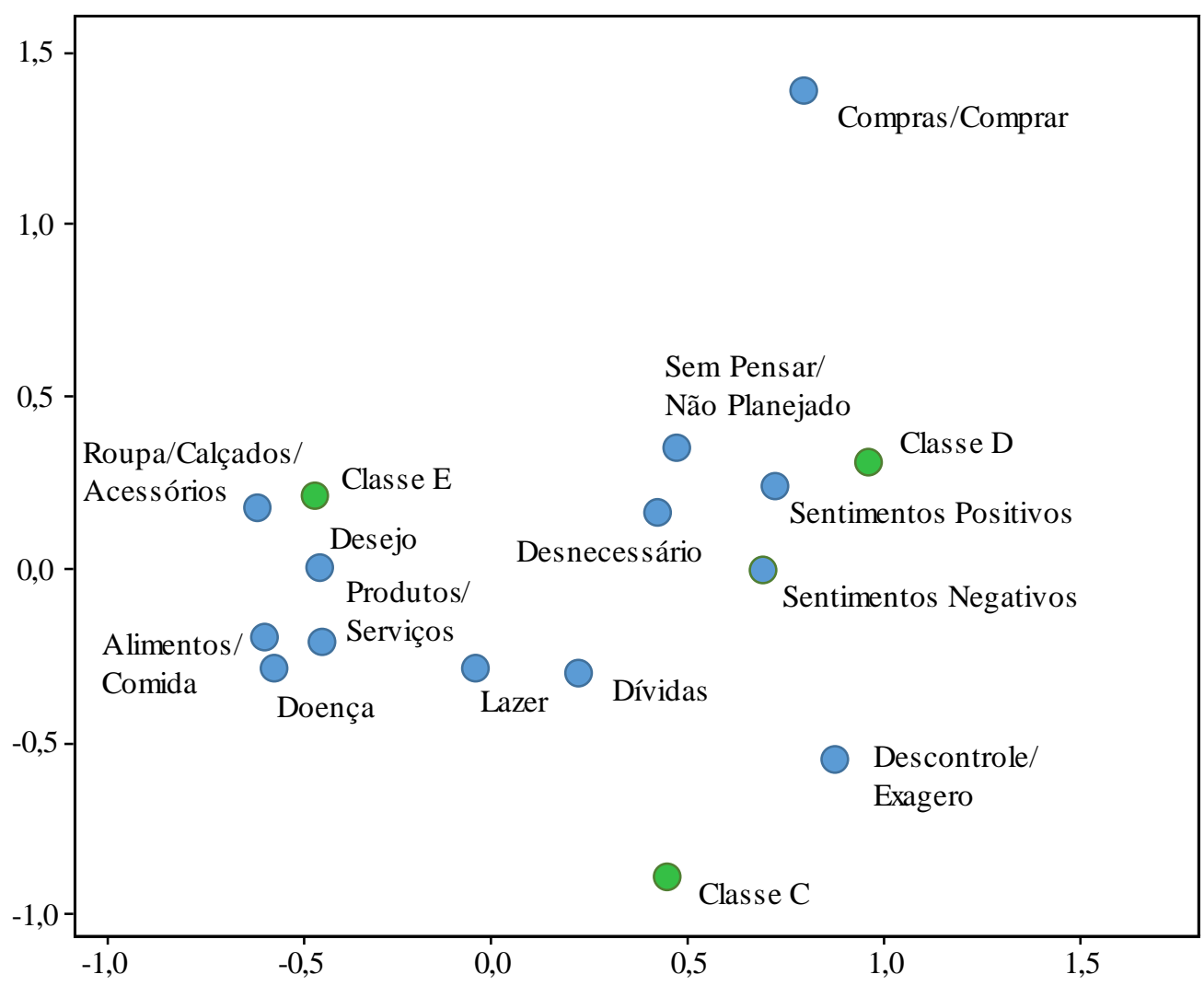

Fonte: Elaborado pelos autores.

Figura 2. Grupos Definidores por Classes de Renda

\section{Discussão dos Resultados}

As categorias que compõem o primeiro quadrante da Figura 1 demonstram três aspectos basilares da representação social do consumo impulsivo. A categoria Descontrole / Exagero, formada por termos como passar dos limites, desequilíbrio, excesso e vício, ressalta tanto a representação negativa do conceito quanto a importância de características individuais do consumidor (Weinberg \& Gottwald, 1982; Dholakia, 2000; Dias et al., 2014). Por outro lado, a categoria Sem Pensar / Não Planejado apenas exprime o significado técnico do termo consumo impulsivo. A presença do grupo, no entanto, reflete a consciência do consumidor de baixa renda quanto às definições do termo e o que de fato o seu ato representa na prática.

No que concerne à categoria Dívidas, observa-se que, de certa forma, há indício da compreensão das possíveis consequências da impulsividade por parte dos consumidores; levando-os, muitas vezes, ao endividamento (Siqueiraet al., 2012; Diaset al., 2014). Apesar de indicar os desdobramentos de uma possível ação guiada por impulso, a importância representacional da categoria Dívidas demonstra que a dimensão racional permeia a construção social do conceito de consumo impulsivo. Entretanto, essa racionalidade que orienta o processamento cognitivo de informações é suplantada pelo processamento emocional no ato de consumo - que passa a tomar a centralidade nas decisões de compra (Araújo \& Ramos, 2010; Porpino \& Parente, 2013).

Dessa forma, a análise dos principais grupos definidores que competem para a representação social do conceito em estudo demonstra que há uma marcada presença tanto de elementos de teor notadamente mais racionais quanto de tonicidade mais hedônica. As duas dimensões coexistem na formação do conceito, sinalizando a alta complexidade do tema (Lima, Goslin \& Matos, 2008). Em síntese, as categorias salientam a multifacetada interação entre os princípios emocionais e cognitivo relacionados ao consumo impulsivo. A busca pelos desejos de consumo conduz o 
indivíduo à ação, mesmo com a ciência dos aspectos desfavoráveis relacionados ao fenômeno. 0 impulso ocasionado pelo forte desejo de consumir o induz a uma irresistível necessidade de agir, muitas vezes indeliberada (Rook, 1987). Contraditoriamente, o indivíduo é impelido ao consumo, mesmo consciente do que representa a ação impulsiva e das possíveis consequências de sua concretização.

Observando-se os grupos definidores de importância periférica, a categoria Roupa, Calçados e Acessórios, constituída por unidades semânticas análogas ao título do grupo, apresenta os principais elementos de consumo que despertam a impulsividade do consumidor. Por se caracterizarem como símbolos cotidianos que transmitem fortes mensagens sociais, os mecanismos da moda acabam por se transformar em fonte concreta de realização e desejo, demonstrando a influência do contexto sociocultural na representação do conceito (Araújo \& Ramos, 2010; Porpino \& Parente, 2013). A combinação de alta sedimentação no habitus social e o forte apelo de prestígio pessoal transformam essa categoria homônima da moda - em um importante definidor de consumo impulsivo na baixa renda. Do mesmo modo, por se tratar de um corpus de pesquisa com poder aquisitivo mais baixo, foram emersas categorias que ressaltam a preocupação com o consumo de itens presentes em seu cotidiano, como Produtos e Serviços (por exemplo: bebidas, gasolina, mobília e transporte público) e Alimentos/Comida.

A categoria Compras/Comprar, formada principalmente pelos termos que lhe intitulam, acena às ações que se materializam no ato em que o fenômeno se desenvolve. 0 grupo definidor ressalta um importante componente que compete à formação do fenômeno em questão: a ação de comprar independente do ato de consumir. A experiência de compra, que se caracteriza como um conjunto de ações que vão desde o transitar em meio a milhares de lojas e vitrines que se oferecem ao comprador até à aquisição propriamente dita, é capaz de despertar sensações e transformar a atividade de comprar em uma das mais gratificantes experiências hodiernas (Lipovetsky, 2007; Baudrillard, 2011).

Em contraste, a categoria Sentimentos Negativos, revela possíveis consequências emocionais derivadas do fenômeno. Tal fator ratifica a complexidade incorrida no processo de consumo impulsivo, indicando que, a pesar de se caracterizar como um evento momentâneo e repentino, há um amplo conjunto de ações ex post relacionadas ao fenômeno. Assim, a ação pontual de consumir de forma impulsiva possui um fim bem delimitado, definido pela consecução do ato a ele relacionado. No entanto, seus desdobramentos podem repercutir por um longo tempo, trazendo fortes consequências tanto financeiras quanto emocionais. Do mesmo modo, o grupo definidor Desnecessário, constituído principalmente pelas palavras e expressões futilidade, inutilidade, desnecessário e produtos supérfluos, destaca a representação negativa do conceito de consumo impulsivo.

Embora não tenha aparecido diretamente na análise, o dinheiro se caracteriza como um componente intimamente relacionado ao fenômeno, permeando todo o seu processo de consecução: é o veículo facilitador da impulsão ao passo que representa a própria punição pelo ato de consumir impulsivamente. 0 dinheiro cumpre assim o papel de porta-voz do paraíso, trazendo ao alcance das mãos todos os desejos de consumo imagináveis. Por outro lado, é o próprio algoz do indivíduo, levando-o a culparse pelas escolhas que buscam satisfações efêmeras e desnecessárias. Na baixa renda, essa relação paradoxal com o dinheiro e o consumo se torna ainda mais evidente: uma espécie de atração por aquilo que repulsa, bem como uma repulsão por aquilo que atrai.

Por fim, os grupos definidores menos consensuais compõem o quarto e último quadrante. Embora as categorias semânticas representem características individuais na representação, elas portam significados importantes para a análise. Em geral, as categorias destacam fatores subjacentes relacionados ao consumo impulsivo. Os grupos ressaltam, mais uma vez, a ambiguidade presente na representação do fenômeno. Ao passo que Lazer, Desejo e Sentimentos Positivos dizem respeito a características, de certa forma, auspiciosas da representação, a categoria Doença revela aspectos prejudiciais. Vale destacar que a categoria Doença é constituída por unidades como distúrbio, neurose, problema e bipolaridade, sinalizando uma fuga da normalidade, e até mesmo da sanidade, pelos consumidores impulsivos. 


\section{CONSIDERAÇÕES FINAIS}

No decorrer do trabalho buscou-se compreender o comportamento impulsivo do consumidor de baixa renda, analisando-se a construção coletiva da compra por impulso por meio da teoria das representações sociais.Por meio da metodologia de evocação de palavras, chegou-se ao resultado que, nessa representação, consumo impulsivo é definido pelos seguintes conceitos: i) falta de planejamento, que aparece como um elemento de tipo funcional ligado diretamente à natureza do fenômeno - a compra não planejada muitas vezes é entendida quase como sinônimo do comportamento impulsivo, definição seminal, presente nos diferentes estudos do tema; ii) descontrole / exagero, elemento de tipo normativo e valorativo que indica excessos; iii) dívidas / endividamento, elemento não estritamente ligado à definição ou entendimento do fenômeno, sendo mais uma consequência ou resultado do consumo impulsivo e tem conotação negativa. Estes três elementos, de natureza normativa e funcional, são permanentes e com maior poder de definição da representação.

Os outros elementos que representam o consumo impulsivo possuem carácter mais contextual, quais sejam: i) desnecessário; ii) compras; iii) sentimentos negativos - tais como infelicidade, frustração, stress, falta de autoestima, entre outros. Os elementos mencionados condizem com a visão de que compra por impulso é um processo ativado emocionalmente, ocorrendo quando o componente emocional se intensifica, reduzindo a capacidade de processamento cognitivo.

Também fazem parte da representação, produtos e serviços de todos os tipos, tais como: roupa, calçados e acessórios, além de alimentos e comida em geral - elementos referidos principalmenteao objeto motivador da compra, ou seja, são elementos contextuais mais flexíveis, factíveis de mudar em outras representações e que são mais afetados pela conjuntura do momento. 0 caráter contextual destes elementos fica evidente quando analisados os grupos definidores por classes de renda. A classe mais baixa está muito mais ligada a elementos contextuais e bens e serviços em particular. Por outro lado, observou-se que a classe D está mais ligada a sentimentos, característica funcional da natureza do fenômeno, e a classe C mais ligada a elementos normativos, de descontrole e exagero.

Vale ressaltar a relevância apresentada pelo conjunto dívidas na representação da compra impulsiva. Caracterizando-se como um elemento definidor de importância central, a categoria destaca bem as consequências negativas da impulsividade. Isso levanta a necessidade de a área do marketing ter outros enfoques e dar margem ao estudo de outros fenômenos que não fazem parte diretamente do consumo, mas que são uma consequência direta deste, como um outro lado da moeda.

Finalmente, as conclusões desta representação social estão restritas ao grupo social estudado e são limitadas pela característica da amostra, não probabilística e não representativa do universo dos consumidores de baixa renda. Esse estudo contribui para o conhecimento acadêmico no que tange à redução da lacuna teórica existente sobre o estudo do comportamento impulsivo em consumidores de baixa renda, assim como também atenua uma lacuna metodológica no campo da administração referente ao uso da técnica de evocação de palavras. Essa pesquisa também fornece contribuições gerenciais, uma vez que apresenta características de um grupo de consumidores possuidor de grande potencial de consumo, possibilitando adequar as estratégias de marketing e venda de empresas que atendem esse segmento.

Espera-se incentivar outras pesquisas nesta área e grupo social, em particular. Também espera-se que novos estudos possam se estender à compreensão do fenômeno por outras variáveis sociodemográficas, como gênero e idade, contribuindo, igualmente, para a ampliação do conhecimento sobre consumidores mais vulneráveis.

\section{REFERÊNCIAS}

Aaker, D. A., Kumar, V., \& George S. D. (1995). Marketing Research (5th ed.). New York: John Wiley and Sons Inc.

Abric, J. C. (2001). Prácticas Sociales y Representaciones. México: Ediciones Covoacén, S. A.

Antoni, V. L., \& Basso, K. (2016). Expectativas em relação ao varejo: Um estudo com as 
consumidoras de confecções e calçados na base da pirâmide social. Revista Brasileira de Gestão de Negócios, 18(62), 593-608.

Applebaum, W. (1951). Studying consumer behaviour in retail stores. Journal of Marketing, 16(2), 32-40.

Araújo, G. P., \& Ramos, A. S. M. (2010). Comportamento de compra por impulso em Shopping Centers: Pesquisa com consumidores de Brasília-DF e Natal-RN. Encontro Nacional da ANPAD, 31. Rio de Janeiro: ANPAD.

Barbiéri, E. S. F. (2015). Representações sociais sobre produção escrita por parte de alunos do ensino fundamental. Dissertação de mestrado, Psicologia Educacional, Centro Universitário FIEO, São Paulo.

Barki, E., \& Parente, J. G. (2010). Consumer behaviour of the base of the pyramid market in Brazil. Greener Management International, 56, 11-23.

Bashar, A., Ahmad, I., \& Wasiq, M. (2013). A study of demografic factors on consumer impulse buying behavior. Journal of Management Research, 13(3), 145-154.

Baudrillard, J. (2011). A sociedade de consumo. Lisboa: Edições 70.

Beatty, S., \& Ferrel, E. (1998). Impulse buying: modeling its precursors. Journal of Retailing, 74(2), 169-192.

Chauvel, M. A., \& Mattos, M. P. A. Z. (2008). Consumidores de baixa renda: uma revisão dos achados de estudos feitos no Brasil. Cadernos EBAPE.BR, 6(2), 1-16.

Christensen, L, S., Siemsen, E., \& Balasubramanian, S. (2015). Consumer behavior change at the base of the pyramid: Bridging the gap between for-profit and social responsibility strategies. Strategic Management, 36(2), 307317.

Clover, V. T. (1950). Relative importance of impulsebuying in retail stores. Journal of Marketing, 15(1), 66-70.

Costa, F. C. X., \& Larán, J. A. (2003). A compra por impulso em ambientes on-line. Revista de Administração de Empresas, 43(4), 36-47.

Dholakia, U. (2000). Temptation and resistance: an integrated model of consumption impulse formation and enactment. Psychology \& Marketing, 17, 955-982.

Dias, S. E. F., Santos, R. M., Martins, V., \& Isabella, G. (2014). Efeitos das estratégias de marketing de compras coletivas sobre o comportamento impulsivo. Revista Brasileira de Marketing, 13(3), 138-151.

Franco, M. L. P. B. (2004). Representações sociais, ideologia e desenvolvimento da consciência. Cadernos de Pesquisa, 34(121), 169-186.
Gupta, S., \& Pirsch. J. (2014). Consumer evaluation of target marketing to the bottom of the pyramid, Journal of International Consumer Marketing, 26(1), 58-74.

Gupta, S., \& Pratish, S. (2016). An exploratory investigation of aspirational consumption at the bottom of the pyramid, Journal of International Consumer Marketing, 28(1), 215.

Hair, J. F. Black, W. C., Babin, B. J., Anderson, R. E., \& Tatham, R. L. (2005). Análise multivariada de dados (5a ed.). Porto Alegre: Bookman.

Hemais, M. W., Casotti, L., \& Rocha, E. (2013). Hedonismo e moralismo: Consumo na base da pirâmide. Revista de Administração de Empresas, 53(2), 199-207.

Kolk, A., Riviera-Santos, M., \& Rufin, C. (2014). Reviewing a decade of research on the "base/ bottom of the pyramid" (BOP) concept. Business \& Society, 53(3), 338-377.

Kollat, D. T., \& Willet R. P. (1967). Consumer impulse purchasing behavior. Journal of Marketing Research, 4, 21-31.

Lawrence, J. B., \& Stanford, M. S. (1999). Impulsivity and time of day: Effects on performance and cognitive tempo. Personality and Individual Differences, 26(2), 199-207.

Lima, I. L. C., Gosling, M., \& Matos, E. B. (2008). Modelagem da compra por impulso de donasde-casa de baixa renda em supermercados de Belo Horizonte. Encontro Nacional da ANPAD, 32. Rio de Janeiro.

Lipovetsky, G. (2007). A felicidade paradoxal: ensaios sobre a sociedade de hiperconsumo. São Paulo: Companhia das Letras.

Lucas, M.,\& Koff, E. (2014). The role of impulsivity and of self-perceived attractiveness in impulse buying in women. Personality and Individual Differences, 56, 111-115.

Mendonça, A. P., \& Lima, M. E. O. (2014). Representações sociais e cognição social. Psicologia e Saber Social, 3(2), 191-206.

Moller, R. C. (1996). A representação social do fenômeno participativo em organizações públicas do Rio de Janeiro. Política $e$ Administração, 3(1), 43-51.

Moscovici, S. (2012). Representações sociais: Investigações em psicologia social (9a ed.). Rio de Janeiro: Vozes.

Muruganantham, G.,\& Brakat, R. S. (2013). A review of impulse buying behavior. International Journal of Marketing Studies, 5(3), 149-160.

Oliveira, M. (2004). Sociais e sociedades: A contribuição de Serge Moscovici. Revista Brasileira de Ciências Sociais, 19(55), 180-186.

Peñaloza, V., Denegri, M., \& Gerhard, F. (2015). Consumo en mercados alternativos para baja 
renta: Un estudio de la Feria de ParangabaBrasil. Polis (Santiago), 14(41), 481-497.

Porpino, G., \& Parente, J. (2013). Antecedentes e consequências da compra impulsiva: Um estudo exploratório. Congresso online - Gestão, educação e promoção da saúde, 2. São Paulo.

Roberts, J., \& Manolis, C. (2012). Cooking up a recipe for self-control: The three ingredients of selfcontrol and its impact on impulse buying. Journalof Marketing Theory \& Practice, 20, 173-188.

Rocha, A, \& Silva, J. (2009). Consumo na base da pirâmide: estudos brasileiros. Rio de Janeiro: Mauad X.

Rook, D. W. (1987). The buying impulse. The Journal of Consumer Research, 14 (2), 189-199.

Santini, F. O., \& Espartel, L. B. (2008). Promoção de distribuição de prêmios: Seus efeitos na compra por impulso e nas intenções de recompra. Encontro de Marketing da ANPAD, 3, EMA.

SPC. Serviço de Proteção ao Crédito. 52\% dos brasileiros fizeram alguma compra por impulso nos últimos três meses, revela SPC Brasil. Recuperado em 20 de fevereiro, 2016, de https://www.spcbrasil.org.br/pesquisas/pes quisa/905

Shahjehan, A., Qureshi, J.A., Zeb, F., \& Saifullah, K. (2011). The effect of personality on impulsive and compulsive buying behaviors. African
Journal of Business Management, 6(6), 21872194.

Siqueira, L. D., Castro, A. D. M., Carvalho, J., \& Farina, M. C. (2012). A impulsividade nas compras pela Internet. Revista Eletrônica de Estratégia \& Negócio, 5(1), 253-279.

Stern, H. (1962). The significance of impulse buying today. The Journal of Marketing, 26, 59-63.

Tinne, W. (2011). Factors affecting impulse buying behavior of consumers at superstores in Bangladesh. ASA University Review, 5, 209220.

Vergara, S. C., \& Ferreira, V. C. P. (2007). Teoria das representações sociais: uma opção para pesquisas em administração. Revista ANGRAD, 8(2), 225-241.

Weinberg, P., \& Gottwald, W. (1982). Impulsive consumer buying as a result of emotions. Journal of Business Research, 10(1). 43-57.

Yurdakul, D., Atik, D., \& Dholakia, N. (2017). Redefining the bottom of the pyramid from a marketing perspective. Marketing Theory, 1(15) 2-15.

Youn, S. (2000). The dimensional structure of consumer buying impulsivity: measurement and validation. Doctoral Dissertation, University of Minnessota, Minnessota, USA.

\section{Social Representation of Impulse Purchasing by Low-income Consumers}

Even though academic researches concerned with impulse purchasing has considerably increased over the last years, there are only few studies with focus on low-income consumers. Therefore, this paper aims to understand impulsive behaviour of low-income consumers analysing the collective construction of impulse purchasing through social representation theory. To this end, we choose short duration structured interview, basing on world evocation technique, as study method. These interviews were carried out over a research corpus constituted by 306 people with distinct sociodemographic characteristics. Results reveal that social representation of impulse purchasing is formed by a multitude of heterogeneous concepts with different aspects among social classes. However, three concepts are highlighted as the most important to understand this phenomenon: lack of planning, lack of control/exaggeration, and debt/indebtedness; they reveal a social construction composed by both normative and functional elements and consequences with negative connotations. Keywords: Impulse Purchasing, Low-Income Consumers, Social Representation. 